\title{
TIJDSCONCEPTEN EN TIJDSBELEVING, EEN PROBLEEM UIT DE INTERCULTURELE COMMUNICATIE. CASE-STUDY: RWANDA
}

\author{
Gerda CAMMAER \\ Departement Communicatiewetenschap (KUL) \\ E. Van Evenstraat $2 A$ \\ $B-3000$ Leuven
}

ONDERZOEKSVELD: Internationale en interculturele communicatie m.b.t. de ontwikkelingslanden

\section{SUMMARY}

\section{CONCEPTIONS OF TIME AND TIME EXPERIENCE, A PROBLEM IN INTERCULTURAL COMMUNICATION. CASE-STUDY: RWANDA.}

The confrontation between people from different cultures causes a lot of problems, most of all communication problems. They are too often considered as only language-problems, but the so-called "cultural-shock" is a lot more comprehensive. Reducing any cultural problem to language troubles, means ignoring the non-verbal and other cultural principles that make cultures so rich and different.

The experience of time and the concepts of time are such principles, rooted in culture and traditions. For the members of the culture in question, these time-principles have become so natural that they remain unexperienced or even unconscious, but they might surprise, even irritate, the members of other cultures. The scientific discipline called "chronemics" examines how humans perceive, structure and use time as communication. Every culture has its own conception of time and its own customs for the use of time. In this sense the Western culture is totally different from the Central African culture in Rwanda. This often causes intercultural conflicts when Europeans working in Rwanda are confronted with the different attitudes towards time of the Rwandese people and vice versa. 
The purpose of this research is to find an answer to the question whether the intercultural communication between Rwandese people and Europeans (sometimes, often, always) is disturbed because of misunderstandings caused by the differences in their time-codes. This survey contains two parts: first, a literature study on intercultural communication and time as a message system with references to the two cultures in question and second, a field study in Rwanda consisting of 120 questionnaires answered by Europeans and Rwandese people who work together.

KEY WORDS: chronemics, communication science, intercultural communication, formal time, informal time, Rwanda

\section{Inleiding}

$\mathrm{Nu}$ de wereld ons dorp is geworden, en onze samenleving multicultureel, worden wij dagelijks geconfronteerd met mensen uit andere culturen. Interculturele communicatie is een alledaags fenomeen geworden. De contacten tussen mensen uit verschillende culturen lopen echter niet altijd even vlot. Communicatiestoornissen, onverdraagzaamheid en soms verbaal en fysiek geweld zijn gradueel oplopende symptomen van interculturele kortsluitingen. Problemen bij interculturele confrontaties vloeien onder andere voort uit een gebrek aan informatie en kennis over andere culturen en het onderschatten van de invloed van cultuur op persoonlijkheid en gedrag, naast een onvoldoende (relativerende) kennis van de eigen cultuur.

Ook in de communicatiewetenschap is de culturele bepaaldheid van in casu het communicatief gedrag lange tijd onderbelicht gebleven. Nu behoort de communicatie tussen mensen uit verschillende culturen ook tot het studiedomein van de communicatiewetenschap. Het jonge deelgebied noemt men "interculturele communicatie". Deze tak van de communicatieleer gaat na hoe het gebrek aan kennis van de (verbale en nonverbale) communicatieregels van een andere cultuur, maar evenzeer de verschillen in waarden, gebruiken en wereldvisie interculturele communicatie bemoeilijken.

Bij interculturele communicatie speelt de nonverbale communicatie een belangrijke rol. Toch wordt dit domein in multiculturele betrekkingen vaak stiefmoederlijk behandeld. Men ziet systematisch over het hoofd dat verschillen in nonverbale communicatieregels, naast andere verschillen een vreemdeling kunnen verwonderen, in de war brengen en zelfs ergeren. Tijdsconcepten en tijdsbeleving zijn zo'n (weinig bestudeerde) vorm van nonverbale communicatie. 
Over de confrontatie van b.v. westerlingen met het Afrikaanse tijdsysteem en andersom, de botsing van het Afrikaanse tijdgevoel met een ongekende westerse gejaagdheid en precisie, is weinig geweten. Ook over de mogelijke conflicten tussen de Rwandese tijdsconcepten en tijdsbeleving en de westerse, hetgeen in dit onderzoek specifiek wordt bestudeerd, is de beschikbare informatie erg schaars. Nochtans worden de vele betrokkenen bij de overvloedige Rwandees-westerse samenwerking bijna dagelijks met de culturele verschillen inzake tijd geconfronteerd. Of deze culturele tijdsystemen echter zo erg verschillen dat de interculturele communicatie tussen Rwandezen en westerlingen omslaat in een interculturele communicatiestoornis, werd tot nu toe nog niet nagegaan. Met dit onderzoek werd getracht een tipje van de sluier over deze problematiek op te lichten. Om in dit opzet te slagen werden verschillende methoden gebruikt: een uitgebreide literatuurstudie, een aantal interviews met deskundigen, een verblijf van vijftien weken in Rwanda (participerende observatie) voor het afnemen van enquêtes bij $R$ wandezen $(n=60)$ en westerlingen $(n=62)$, die in Rwanda met leden van de andere cultuur samenwerken.

De hierna volgende tekst bestaat ten eerste uit een korte uiteenzetting van wat de studie van tijd als nonverbaal kanaal inhoudt. Vervolgens wordt theoretisch, hoofdzakelijk op basis van de literatuur, de tegenstelling beschreven tussen de twee bestudeerde culturele tijdsystemen. In het derde deel wordt een meer verfijnd, maar vooral meer genuanceerd beeld geschetst van tijd en tijd-problemen als (al dan niet verstorende) factor in de interculturele samenwerking van westerlingen en Rwandezen in Rwanda, gestaafd door de resultaten van ons onderzoek. Tot slot volgen als besluit enkele persoonlijke beschouwingen over de resultaten van deze studie en hun ruimere betekenis.

\section{Zeg het met tijd ...}

Tijd spreekt letterlijk door tikken, bellen, klokkegelui, figuurlijk door mee te praten in ons leven. Tijd regelt onze handelingen, beïnvloedt onze gevoelens, verduidelijkt relationele aspecten en bepaalt mee ons wereldbeeld. Tijd kleurt onze acties en interacties. Tijdservaringen zijn echter hoofdzakelijk onbewust: tijd spreekt een stille taal. Hall vestigde met zijn boek "The silent language" (1959) de aandacht op de communicatieve kracht van tijd. POYATOS (1983) introduceerde de term "chronemics" om de studie van tijd te benoemen. Naar analogie met "proxemics", de studie van de ruimte in communicatieve context, vindt hij dat chronemics een essentieel onderdeel vormt van de analyse van menselijk gedrag. Volgens BURGOON e.a.(1989:139), die het begrip het duidelijkst definieerden, is chronemics de studie van de manier waarop mensen tijd waarnemen, structureren en gebruiken als communicatie. $\mathrm{Zij}$ onderscheiden een psychologisch, biologisch en cultureel waarneembaar niveau waarop men tijd kan bestuderen. De culturele 
tijdsoriëntatie is van de drie het dichtst betrokken bij communicatie. Elke cultuur (1) heeft haar eigen opvatting over en definitie van tijd en heeft eigen vastgelegde patronen om met tijd om te gaan. Als tegen deze normen gezondigd wordt, reageren mensen erg gevoelsgeladen en ervaren deze overtredingen als negatieve boodschappen.

Begrijpen wat tijdsnormen juist zijn is niet eenvoudig, vooral omdat in elke cultuur drie tijdsystemen werkzaam zijn: technische tijd, formele tijd en informele tijd, hier gerangschikt volgens een afnemende graad van bewustzijn waarmee mensen tijd hanteren.

Technische tijd is het minst relevant voor de studie van tijd als communicatieve code. Het betreft de wetenschappelijke en exacte meting van tijd, een koele, logische benadering van tijd door b.v. astronomen en wiskundigen.

Formele tijd maakt meer deel uit van het dagelijks leven. Dit is de traditionele manier waarop een cultuur tijd beschouwt. Het is een formeel bewust uitgedacht systeem om tijd te meten. In onze westerse cultuur wordt alles geregeld door een kalender die verschillende cyclische en hiërarchische eenheden bevat. In andere culturen maken de fasen van de maan, de zomer- en winter-zonnekeerpunten en de lente- en herfst-equinoxen de formele tijd uit. Andere elementen van dit systeem dat we formeel leren is hoe de cultuur gebeurtenissen ordent, het soort cycli die men erkent, de waarde die men hecht aan tijd, wat "duur" betekent en de graad van tastbaarheid en (on)zekerheid die men aan de tijd toekent. Doordat dit formeel tijdsysteem zo erg geworteld is in tradities, verdraagt men niet dat anderen ermee knoeien. Dit deel van de tijd verandert niet of zeer moeilijk (b.v. het invoeren van zomer- en winter-uur).

Informele tijd is het interessantste maar moeilijkst te verstaan systeem van de drie. Informele tijdsdelen zijn losjes gedefinieerd, zijn niet expliciet bedacht en werken typisch buiten het bewustzijn om. Ze nemen de vorm aan van regels en verwachtingen die we in onze cultuur leren, maar het is onduidelijk wanneer en of we al deze regels leren. Typische informele tijdsbepalingen zijn variabel in duur en wijzigen naargelang de omstandigheden (b.v. binnenkort, dadelijk, in een minuutje, straks,...). Ook tijdkarakteristieken als dringendheid, verveling, stiptheid, tijdschikking, aankomst-tijdstip op afspraken en dergelijke behoren tot de informele tijd. De informele tijd, concepten en beleving, is het moeilijkste en minst bestudeerde domein binnen de studie van tijd. Bij het vergelijken van culturen inzake tijd zijn vooral deze informele tijd en de formele tijd belangrijk. 
Deze indeling, die we hier besproken hebben op basis van BURGOON e.a. (1989 : 146-147), wordt toegeschreven aan HALL, die ze ook het meest heeft uitgewerkt. HALL bestudeerde de culturele verschillen inzake tijdsconcepten en tijdsbeleving. Hij beschouwt tijd als een taal, een communicatief systeem: tijd communiceert, "time talks". Om tijd te bestuderen ontwierp hij een uitgebreid begrippenkader naar analogie met het fonologisch model (HALL $1959: 100-102$ ). Zijn theorie en terminologie zijn de leidraad in deze studie van het intercultureel contrast tussen de Rwandese tijdsconcepten en tijdsbeleving en de westerse en de mogelijke problemen die dit kan veroorzaken bij het samenwerken van de leden uit beide culturen in Rwanda.

\section{Quand un Belge a une montre, un Rwandais a du temps ...}

Een eerste (theoretische) confrontatie van de tijdsconcepten en de tijdsbeleving kenmerkend voor de westerse cultuur met deze die de Centraal-Afrikaanse cultuur karakteriseren, gebaseerd op gegevens die we hierover bij uiteenlopende literaire bronnen (2) vonden, leert meteen hoezeer de culturele tijdsystemen van elkaar verschillen. Zowel wat betreft de formele tijd als de informele tijd zitten de bestudeerde culturen op een andere golflengte. Een gebrek aan kennis van de nonverbale communicatieregels die dit cultuurspecifieke tijdsbegrip en tijdsbeleven bepalen kan dan ook voor (onaangename) verrassingen zorgen bij interculturele contacten van westerlingen met Afrikanen. In de huidige westerse hoog-technologische maatschappijen heeft men een zeer nauwkeurig waardebesef van tijd: er heerst zelfs een tijdsobsessie. Men levert er koortsachtig strijd voor meer tijd en tegen de tijd. Traditionele Afrikaanse samenlevingen daarentegen (b.v. de Rwandese), hechten minder belang aan de tijd: deze overwegend agrarische maatschappijen stellen de mens, diens activiteiten en de natuur centraal. Niet de tijd bepaalt, de tijd wordt bepaald.

\section{Formele tijd}

Voor het bepalen van tijd, het afbakenen en benoemen van tijdsdelen, gebruikt men in het westen vooral rekenkundige begrippen. De formele tijdsdelen worden er stuk voor stuk uitgedrukt als veelvouden van de tijdseenheden (minuten, seconden, uren, dagen enz.), geteld met behulp van uurwerken en kalenders. De Rwandese formele tijdsdelen, bestaande uit activiteiten, seizoensgebonden eigenschappen en andere gebeurtenissen uit het dagelijks leven van dit bijna uitsluitend uit boeren bestaande volk (nu nog 95\%) vormen hiermee een schril contrast (beschreven in DESOUTER, 1982 : 170-173). In de Centraal-Afrikaanse cultuur is tijd een kleurloze onbepaalde categorie zolang er geen concreet feit optreedt dat aan de tijd een betekenis geeft. Voor een Rwandees bestaat er alleen tijd van dit of dat, tijd voor dit of dat, eigen aan 


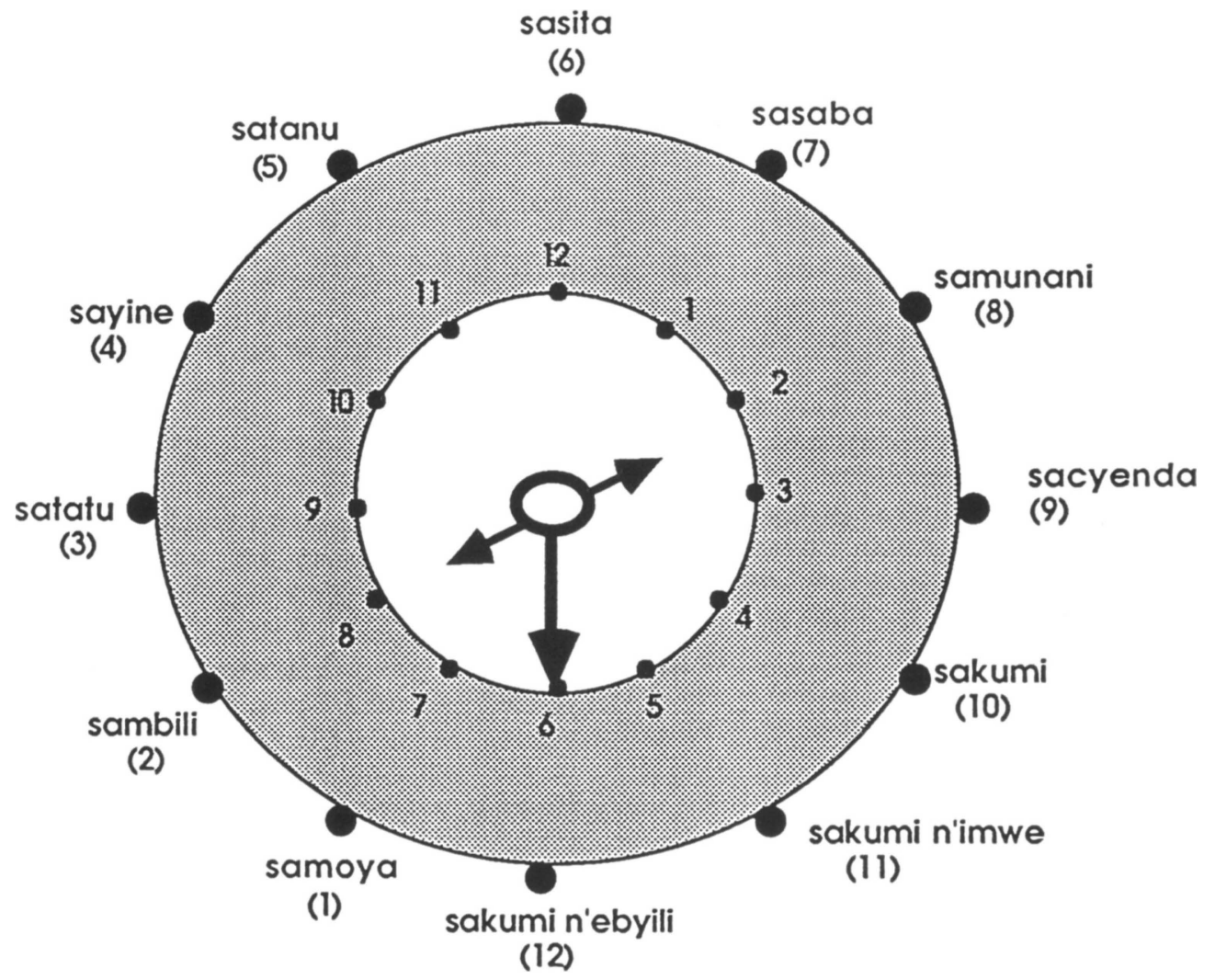

Figuur I - Klok met westerse en Rwandese uren. 
het een of het ander. Slechts als de tijd door een handeling of gebeurtenis wordt afgebakend, wordt hij benoemd en treedt hij uit de anonimiteit: het wordt de tijd van dat evenement (KAGAME, 1975: 114).

Het beschrijven van het tijdsverloop aan de hand van gebeurtenissen en activiteiten komt bij de met digitale horloges en strikte kalenders vertrouwde westerling irreëel over. Zeer weinig Europeanen en Amerikanen hebben nog voeling met zon en maan als tijdsbepalers. De westerse tijd is een volledig vastgelegde berekende tijd, een gesynthetiseerd systeem waarvan de onderdelen kunnen opgeteld worden. Het is een op zichzelf staande entiteit die met de mensen meeloopt. De Rwandese tijd is een beleefde, variabele tijd. Men mag echter niet vergeten dat onze tijd ook ooit volledig beheerst werd door de natuur.

In beide culturen is het tijdsysteem gebaseerd op hun economie. In het westen beantwoordt het aan de noden van een hoog technologische maatschappij, met volledige industrialisatie, ver doorgedreven tertialisering en informatisering, waarin alles draait rond efficiëntie en winst. In Rwanda is het tijdsysteem aangepast aan de noden van een traditionele landbouwgemeenschap. Op dit ogenblik echter maakt Rwanda een snelle evolutie van verwestersing door. Dit heeft ook zijn weerslag op het culturele tijdsysteem: de maand (vroeger maanmaanden) en de week (oorspronkelijk van 3, later van 5 dagen) werden aangepast, het jaar begint nu met Januari (Mutarama) in plaats van met (onze maand) September (Nzeli) en duurt slechts 12 maanden (i.p.v. 13) en er werden klok-uren ingevoerd ter vervanging van de beschrijving van activiteiten van boeren en herders en zonnestanden als opeenvolgende momenten in de dag.

Voor dit laatste werd een geschikte terminologie ontleend aan het Kiswahili. Opmerkelijk is dat men een dag veel meer natuurgetrouw onderverdeeld in 12 uren dag en 12 uren nacht. De dag-uren beginnen om 7 uur 's ochtends onze tijd (hun eerste uur) en eindigen om 6 uur's avonds (in het Kiswahili vertaald als 12e uur). De nachturen lopen van 7 uur 's avonds in onze terminologie (in het Kiswahili: het eerste uur) tot 6 uur 's ochtends (bij hen het 12e uur) (zie figuur 1: klok met westerse en rwandese uren). De dag komt overeen met de periode dat het licht is en men de warmte van de zon voelt, duidelijk onderscheiden van de nacht. Een afrikaan denkt niet aan dagen als een volledige rotatie van de aarde in 24 uur, de dag heeft zijn specifieke rol en de nacht de zijne (KAGAME, 1975:119).

Alle hoger beschreven veranderingen geraken echter slechts langzaam ingeburgerd. De stedelijke en hoger geschoolde burgers hebben op dit ogenblik hierin een zekere voorsprong. 
Ook wat betreft de andere kenmerken van de formele tijd is het verschil tussen de twee culturen en hun centrale waarden treffend. In het op efficiëntie gerichte westen ordent men zijn tijd. Men is er voortdurend gericht op vooruitgang en vernieuwing: een rechtlijnige constante evolutie, mee met de tijd. Tijd is in dit proces iets kostbaars, iets waar men zuinig moet mee omspringen. Men gebruikt tijd, profiteert er van om iets te realiseren. Men verliest tijd door niets te doen. Men wint tijd door zich harder in te spannen. De tijd is beperkt. Tijd is kostbaar. Tijd is geld. De mens is gebonden door de tijd en schikt zich ernaar. Voor een Rwandees is dit vreemd: de tijd is er voor de mensen die tijd maken zoveel ze willen. Tijd wordt geordend zoals de gebeurtenissen zich ordenen. Tijd verloopt dus cyclisch, want gebeurtenissen keren telkens terug. Deze cycli verlopen wel telkens op een hoger plan: de tijd is ook voor een Rwandees onomkeerbaar (men wordt b.v. hoe dan ook ouder). Cycli, natuurlijke en menselijke, met rituelen op hun hoogtepunten determineren het levensritme in Rwanda (KAGAME, 1975 : 125).

Voor een Rwandees speelt het verleden een belangrijke rol: het is de voedingsbodem voor het heden, de verzamelplaats van al het gebeurde waaruit al het huidige is ontstaan en waaraan het zijn betekenis ontleent. In het Westen is het verleden veel minder belangrijk: buiten het vullen van geschiedenisboekjes, in het beste geval ervan leren, en het bijhouden van wat sentimentele souvenirs of het opgraven van verjaarde cultuurrestanten, doet men er niet veel mee. Men keert het verleden de rug toe.

De twee culturele tijdsystemen verschillen verder, wat betreft hun formele tijdgedrag, inzake planning, afspraken en toekomstvisie. Een westerling moet toekomstgericht leven, plannen, (bereikbare) resultaten voorop stellen en doelen stellen: allemaal waarden sterk verbonden met de moderne economie. In Rwanda is men hiermee (nog) niet vertrouwd. Het ligt niet in hun aard zich met de toekomst bezig te houden: men wacht af wat er te gebeuren staat. Voorspellingen zijn voorbehouden aan zieners. Het nabije en het concrete telt. Op nationaal vlak worden er wel langlopende plannen gemaakt binnen het kader van de globale ontwikkelings-politiek, maar voor de doorsnee Rwandees blijft planning een hol begrip. Dit botst soms op westers onbegrip als het stockbeheer of een (tijd)schema in het honderd loopt.

Inzake afspraken leiden de culturele "tijd"-verschillen waarschijnlijk soms tot menselijke kortsluitingen: hier lopen de tijdsbelevingen helemaal uit elkaar. De westerling die met een goed gevulde, mooi geschematiseerde agenda en strikt gechronometreerd tijdschema afspreekt met een doorsnee Rwandees, staat veelal na een kwartier nog vruchteloos te wachten. Voor zijn Rwandese partner kan er altijd iets tussen komen, b.v. iemand onderweg tegenkomen. Men springt in Rwanda erg soepel om met afspraakuren. Behalve als men zegt "om tien uur daar, blanke tijd" : dat is stipt! Dit verwijst ook naar de verandering die er momenteel plaatsgrijpt, vooral 
als gevolg van de jarenlange aanwezigheid van westerlingen en het ingevoerde schoolsysteem. Ook onder impuls van het beleid van president Habyarimana wordt strikter met tijdslimieten omgesprongen (b.v. in de ambtenarij).

\section{Informele tijd}

Het wazige karakter van de informele tijd, met tijdsdelen die bepaald worden door de context waarin ze gebruikt worden, lijkt nauwer aan te sluiten bij een Afrikaanse tijdsbeleving. Toch blijkt het "rekbare" van de westerse informele tijdsbepalingen niet elastisch genoeg om de enorme soepelheid van de overeenkomstige $R$ wandese bepalingen te omvatten. Dit is voorlopig echter slechts een persoonlijke indruk. Over de informele tijd is weinig gekend. Voor het westen heeft HALL al een eerste stap gezet in de richting van een bruikbare theorie (HALL, 1959 : 149-160). Een analyse van gebruik en opvattingen inzake informele tijd in een Centraal-Afrikaanse cultuur is vooralsnog niet voor handen.

Wat betreft stiptheid spannen Europeanen en Amerikanen de kroon. Te laat komen is een slechte eigenschap. Een Rwandees springt minder minutieus om met afspraakuren. Dit werkt (onvoorbereide) westerlingen enorm op de zenuwen. Bovendien wordt iemand laten wachten voor een onderhoud in Afrika nog meer gebruikt als uiting van macht. De niets vermoedende westerling voelt zich beledigd door dat lange antichambreren. Is de reden van zijn bezoek iets "dringend", dan lijkt die wachttijd nog trager te verlopen. Hij verveelt zich en verspilt zijn kostbare tijd. Zijn keurige planning wordt overhoop gehaald. Hij moet een nieuwe agenda opstellen. Hij moet zijn tijdschema herwerken. Als hij uiteindelijk wordt ontvangen blijkt hij niet de enige genodigde: in een "polychrone" (3) cultuur worden allerlei zaken tegelijkertijd geregeld. De betrokkene gaat vermoedelijk naar huis met een verhoogde bloeddruk, en waarschijnlijk meer ergernis dan bereikte resultaten, maar hij heeft wel veel geleerd over de manier waarop Afrikanen informeel tijd beleven. Voor hen is dit alles een toepassing van het kenmerk van de tijd: soepelheid.... le temps est élastique! Alle tijdsdelen zijn rekbaar en de mens zet die naar zijn hand.

\section{Zoals het klokje in Rwanda tikt ...}

Op basis van het literatuuronderzoek kan men stellen dat er in de confrontatie van de twee culturele tijdsystemen, het westerse en het $R$ wandese, voldoende conflictstof aanwezig is om de interculturele communicatie te doen omslaan in een interculturele communicatiestoornis. Als men deze uitgangspunten voor het onderzoek toetst aan de uiteindelijke resultaten (de antwoorden op de enquêtes), moet een en ander rechtgezet worden, vooral wat betreft de formele tijd. 


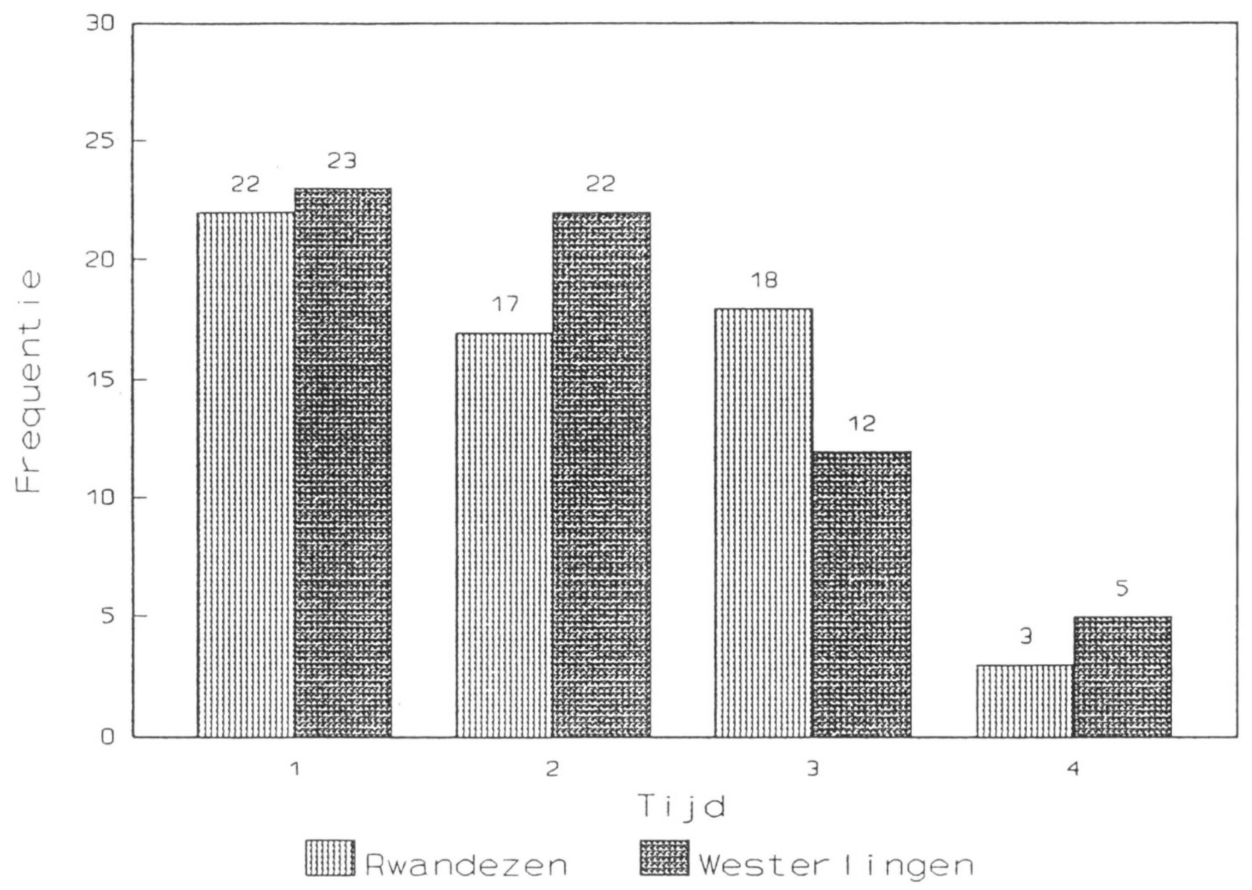

Grafiek 1 - Hoe goed schatten Rwandezen en westerlingen de duur van het gesprek?

\section{Legende:}

$1=$ juiste duur

$2=5-10 \mathrm{~min}$. fout

$3=10-20 \mathrm{~min}$. fout

$4=$ meer fout 
Horloges, agenda's en kalenders zijn niet (langer) exclusief westers. De vooronderstellingen dat westerse tijdsconcepten voor de Rwandezen vreemd zijn en dat zij moeite hebben met het bepalen van datum en uur, zijn op zijn minst te sterk geformuleerd. De formele tijdsbepalingen maand, week en dag zijn door de Rwandezen goed tot zeer goed gekend. Zonder een horloge het uur bepalen lukt hen heel aardig, de juiste datum zeggen voor een meerderheid onder hen ook. Met een eeuw en een seconde, twee uiterste polen van de tijdberekening, hebben zij meer last. Dat Rwandezen tijdsconcepten hanteren die verwijzen naar natuurfenomenen, maanmaanden, zonne-uren, klimatologische seizoenen, is al evenzeer achterhaald. De seizoenen zijn door hen eerder weinig gekend, waarschijnlijk omdat het groot en klein droog-seizoen en het groot en klein regen-seizoen in Rwanda niet voldoende van elkaar verschillen en omdat het voor de rest eerder aanduidingen voor bepaalde agrarische activiteiten betreft, die daarnaast ook gebruikt worden als tijdsbepalingen. Maan-maanden worden quasi niet meer gebruikt.

Rwandezen zien de tijd nog steeds als een reeks cycli, maar ze refereren ondertussen hoofdzakelijk naar de toekomst, niet (meer) naar het verleden (hoewel de westerse groep hier zijn twijfels over heeft). Een Rwandees kent over het algemeen zijn exacte leeftijd niet, en het tellen van iemand anders' leeftijd is ook een probleem: Rwandezen zien de tijd niet als een gesynthetiseerd systeem waarvan men de delen kan optellen. Men schat iemands leeftijd door zijn uiterlijk te bestuderen en na te gaan of de persoon in kwestie nog nuttig is voor de samenleving. De eigen geboortedatum onthoudt men door een belangrijke gebeurtenis ergens uit die tijd te onthouden. Het schatten van de duur van een activiteit behoort duidelijk wel tot hun tijdskennis (zie grafiek 1: schatten van de duur van het gesprek), en dat tijd geld is, dat de mens slaaf is van de tijd of dat tijd moet gestructureerd worden, wordt door hen volmondig beaamd. Rwandezen komen wel nog regelmatig (te) laat, en dat lokt zoals voorspeld reacties uit van westerse werkgevers en/of collega's.

Inzake de informele tijd komen de voorspellingen meer uit. Westerlingen tolereren veel kleinere marges om te laat te komen dan de Rwandezen, ook voor zichzelf: zij excuseren zich vlugger als ze te laat komen op een afspraak (met een vriend) (zie grafiek 2: na hoeveel tijd dat men te laat is excuseert men zich?). Hoewel het "iemand laten wachten" als indicator van macht in Rwanda niet frequent en consequent wordt toegepast, is de ervaring te moeten wachten alvorens men ontvangen wordt voor een onderhoud met een hoog geplaatst persoon er niemand vreemd. Westerlingen hebben het moeilijker met dat antichambreren dan de Rwandezen (zie grafiek 3: na hoeveel tijd tevergeefs wachten op een onderhoud stapt men op?).

Rwandezen ontvangen geregeld uitgebreid bezoek tijdens het werk: sociale relaties komen in Rwanda op de eerste plaats en tijdens een bezoek of ontmoeting ligt het werk en de tijd stil. Deze verlegging van prioriteiten stoort de helft van de wester- 


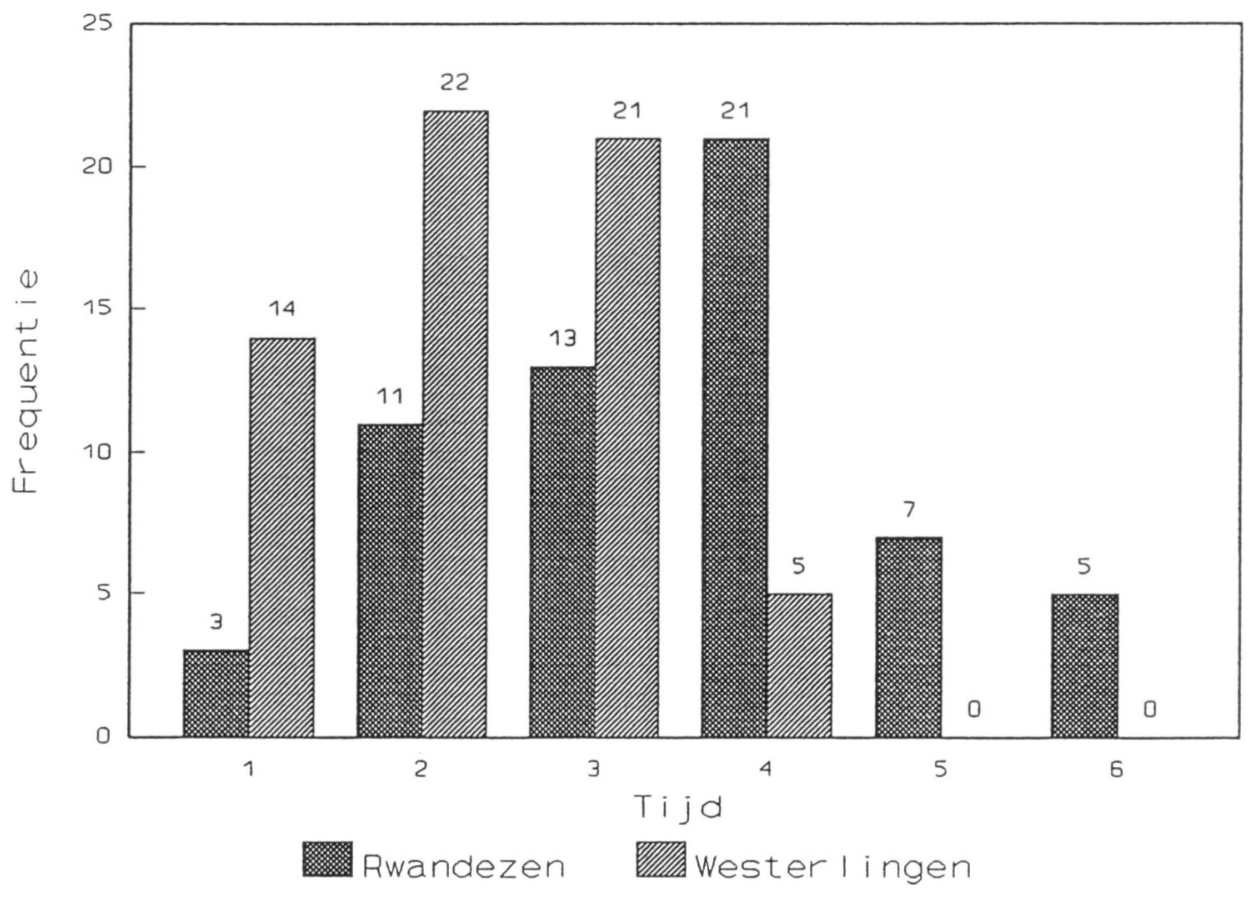

Grafiek 2 - Na hoeveel tijd dat men te laat komt excuseert men zich?

\section{Legende:}

$1=1-5 \mathrm{~min}$. te laat

$2=5-10 \mathrm{~min}$. te laat

$3=10-20 \mathrm{~min}$. te laat

$4=20-60 \mathrm{~min}$. te laat

$5=60-120 \mathrm{~min}$. te laat

$6=120 \mathrm{~min}$. of meer te laat. 


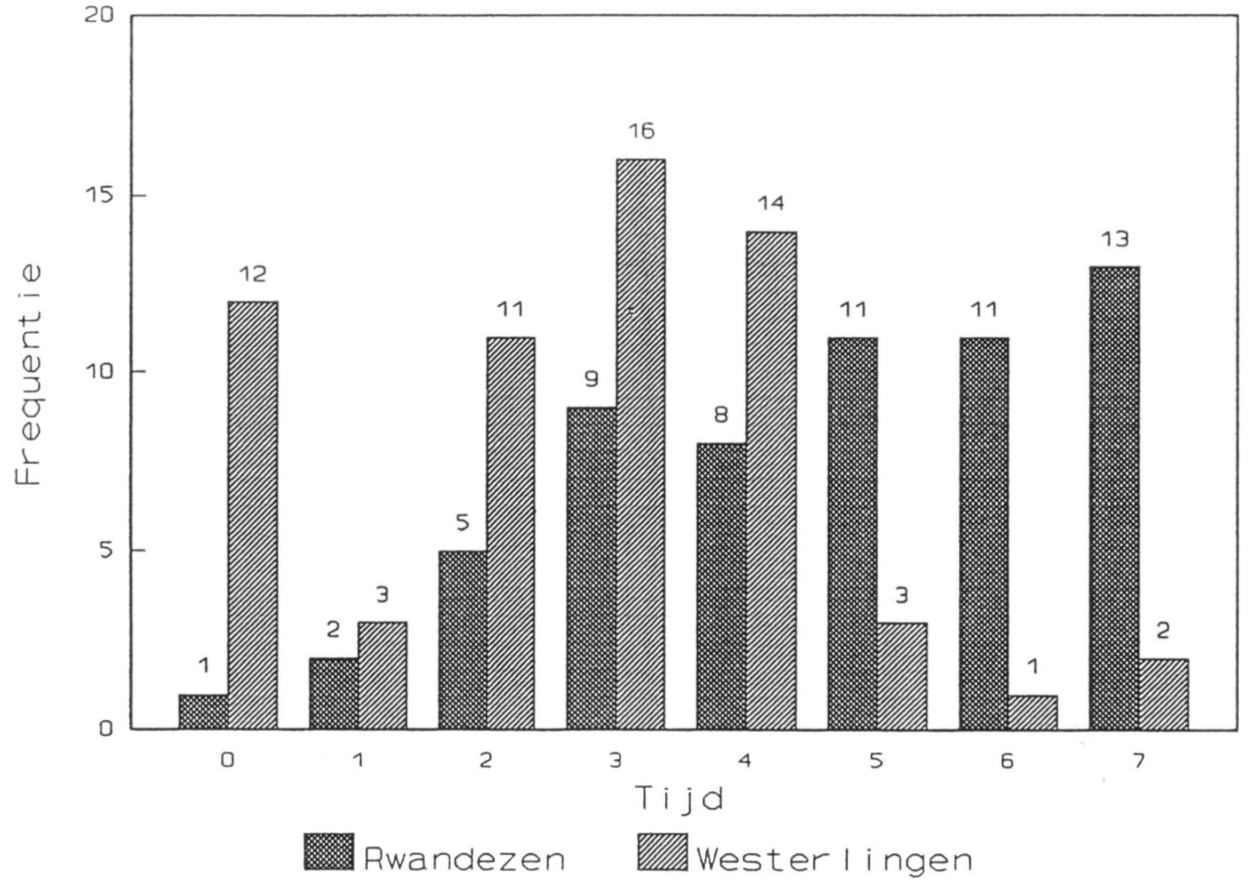

Grafiek 3 - Na hoeveel tijd tevergeefs wachten op een onderhoud stapt men op?

\section{Legende:}

$0=$ geen antwoord, weet niet

$1=$ minder dan $15 \mathrm{~min}$.

$2=15-30 \mathrm{~min}$.

$3=30-60 \mathrm{~min}$.

$4=60-120 \mathrm{~min}$.

$5=120-180 \mathrm{~min}$.

$6=$ meer dat $180 \mathrm{~min}$. - een dag.

$7=$ meerdere dagen. 
lingen omdat dit de efficiëntie, organisatie en continuïteit van het werk hindert. Men kan dan ook gerust stellen dat hier twee waarden botsen: het (westerse) efficiëntiestreven en de (Rwandese) solidariteit. Men kan dit conflict ook beschouwen als een botsing tussen een polychrone en een monochrone cultuur: het ontvangen van bekenden en er uitvoerig mee babbelen tijdens de werkuren gaat evenzeer in tegen de westerse gewoonte activiteiten te scheiden en gescheiden te houden (monochronie).

"Dringendheid", het gevoel dat de tijd trager lijkt te lopen naarmate de nood hoger is, en "activiteit", de opvatting dat men moet bezig zijn om de tijd te doen vooruit gaan, zijn twee informele tijdsconcepten waarover men moeilijk met vragen meer te weten kan komen. We hebben wel de indruk dat dit noties zijn waar westerlingen veel sterker mee leven dan Rwandezen. Zo is het "ergens gewoon zitten niets doen", hetgeen door westerlingen wordt aangevoeld als "tijd verspillen" vermits de tijd doorloopt zonder dat men zelf vordert (in het werk v.b.), in de ogen van een Rwandees geen kwestie van inactiviteit of inefficiëntie: dit is gewoon een activiteit tussen datgene dat eraan vooraf ging en datgene wat volgt (zie figuur 2: mensen die gewoon ergens zitten (en een praatje maken), verspillen volgens afrikaanse tijdnormen geen tijd).

Het informele gebruik om een vaste tijdschikking te hanteren, zelfs om te eten, wordt door $\mathbf{R}$ wandezen anders geïnterpreteerd. $\mathrm{Zij}$ verstaan onder "iets op een vast tijdstip doen" dat men een bepaalde handeling steeds na een zelfde activiteit uitvoert, b.v. eten telkens het werk beëindigd is, ongeacht welk uur het op dat ogenblik is. Voor westerlingen betekent een vast tijdstip om te eten een vast uur, een precieze tijdsbepaling, waarop men eet: b.v. het is 12 uur, dus etenstijd. Inzake aankomsttijdstip op een afspraak, voor of op het afgesproken uur (displaced-point-pattern) of ergens errond (difused-point-pattern), wordt in Rwanda het laatste algemeen toegepast: men komt op bijeenkomsten ergens rond het afgesproken tijdstip aan, meestal ruim (te) laat.

Tenslotte is er een algemene karaktertrek die het $\mathrm{R}$ wandese tijdsysteem onderscheidt van het westerse: het rustiger leef-en werkritme. Haast is in $\mathrm{R}$ wanda een verfoeilijke eigenschap ("wie gehaast is vergeet het doel van zijn bezoek"), geduld en kalmte staan er erg hoog aangeschreven. Wachten valt hen veel minder zwaar dan een doorsnee westerling: met geduld en veel tijd bereikt men immers veel meer dan met kracht en woede ("wie lang leeft, melkt de koe die men hem verbood te melken"). Westerlingen verwijten hun Rwandese collega's een gebrek aan efficiëntie, een gebrek aan doorzettingsvermogen, een te laag (werk-)tempo enzomeer. Volgens de Rwandezen zijn de westerlingen tijd-freak en tijd-ziek: ze lijden aan een chronische gejaagdheid. 


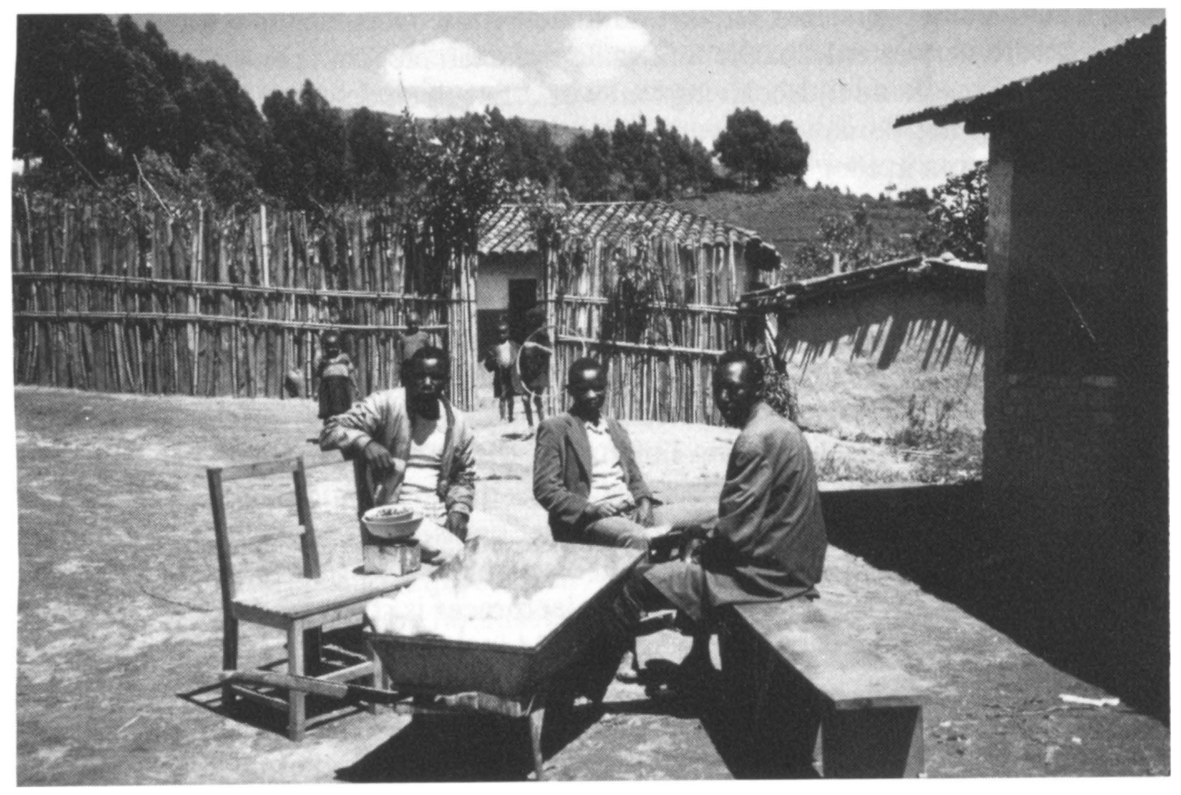

Figuur 2-Mensen die gewoon ergens zitten (en een praatje maken) verspillen volgens Afrikaanse tijdnormen geen tijd. 
Als deze verschillen in informele tijd-gedragingen niet voldoende of slechts vaag bleken uit de rechtstreekse antwoorden op de vragen, hetgeen te wijten is aan die vragen en aan het onderwerp dat moeilijk in vragen te vatten is, dan komen zij toch voldoende uitgesproken naar voor in de vrije commentaren, vooral die van de westerlingen. Men mag dus stellen dat de uitgangspunten inzake de informele tijd en de wijze waarop de westerse en de Rwandese cultuur hierin verschillen, grotendeels worden bevestigd. De mate waarin deze twee soorten tijdsbeleving botsen, is echter in de realiteit veel kleiner dan aanvankelijk werd verondersteld.

\section{Besluit}

De belangrijkste resultaten van deze studie zijn samen te vatten in twee stellingen. In de eerste plaats blijkt dat er in Rwanda, wat de formele tijd betreft, in de praktijk nog maar weinig overschiet van de traditionele tijdsconcepten: de Rwandese tijd is als het ware verwesterd. Inzake informele tijd daarentegen, is er wel degelijk nog een verschil tussen de tijdsbeleving van westerlingen en deze van Rwandezen. Ten tweede blijkt dat de culturele verschillen inzake tijdsconcepten en tijdsbeleving minder scherp en in elk geval minder storend blijken te zijn in de dagelijkse realiteit dan verwacht werd op basis van het literatuuronderzoek.

Het onderscheid tussen de onderzoeksresultaten inzake formele en informele tijd is te verklaren door de eigen aard van deze twee soorten tijd. De soort tijd die HALL "formeel" noemt, kreeg die naam omdat hij kan aangeleerd worden. In feite is dit onderdeel van een cultureel tijdsysteem meer onderzoeksmateriaal voor de semantiek en de antropologische of etno-linguïstiek. Men kan dit bestuderen en leren aan de hand van de betreffende woordenschat, net zoals een vreemde taal. Het jarenlange onderricht in Rwanda door westerlingen in het Frans, heeft ongetwijfeld de nodige westerse tijd-terminologie ingelepeld. Dit betekent niet, dat nu het onderwijs hoofdzakelijk in het Kinyarwanda geschiedt, dit leerproces is stil gelegd, integendeel. De Gregoriaanse kalender is ondertussen, vertaald in de Rwandese taal, officieel ingevoerd. Dit alles zorgt er voor dat het westerse formele tijdsysteem de traditionele Rwandese natuurgebonden tijdsnoties stilaan verdringt. Het zal echter wel nog een tijd duren vooraleer de ganse bevolking vlot deze nieuwe tijdtermen kan hanteren. Op dit ogenblik zit men in een overgangsfase: het oude systeem heeft men grotendeels laten vallen, maar het nieuwe heeft diens plaats nog niet helemaal (of voor iedereen) ingenomen.

Wat betreft de informele tijd komen in de onderzoeksresultaten meer interculturele verschillen en wrijvingen tot uiting. Vooral de westerse groep voelt de verschillen wat betreft beleving van stiptheid, activiteit, dringendheid, tijdschema's, leefritme en werktempo, kortom van de informele tijd goed aan. Van Rwandese zijde worden 
bepaalde typisch westerse eigenschappen en uitspraken in verband met tijd (b.v. "op tijd komen is een goede eigenschap") volmondig beaamd en worden de culturele verschillen op het eerste zicht minder scherp aangevoeld. Toch blijkt vaak uit een verdere bevraging, dat $R$ wandezen ook de informele tijd in andere termen uitdrukken en deze veel losser beleven. Rwandezen excuseren zich b.v. duidelijk minder vlug als ze te laat komen op een afspraak dan westerlingen: zij beschouwen later toekomen minder vlug als te laat toekomen. Dat het hier de informele tijd betreft, dit wil zeggen een hoofdzakelijk niet bewuste tijdbeleving en een niet op bewuste wijze aangeleerde tijd, verklaart voor een belangrijk deel het feit dat dit deel van een cultureel tijdsysteem niet zo gemakkelijk te veranderen of aan te passen is, en dat de culturele verschillen op dit vlak beter aangevoeld worden. Bovendien is dit aspect er voor verantwoordelijk dat men op een verschillende beleving van tijd niet is voorbereid: dit is grotendeels ongekend terrein.

Omwille van dit niet bewust karakter van de informele tijd, en omdat er zo weinig over geweten is, is het moeilijk er een concreet onderzoek over op te zetten. HALL werkte al een passend begrippenkader uit, maar dit operationaliseren brengt veel praktische problemen mee. Een vragenlijst is waarschijnlijk ook geen goede methode om dit onderwerp echt te doorgronden, maar wel nuttig als instrument voor een eerste kennismaking met de informele tijd. Het is dan ook vooral in deze zin, namelijk verkennend, illustrerend en verifiërend, dat deze studie betekenis heeft.

Om een verklaring te zoeken voor de tweede vaststelling, het feit dat de interculturele verschillen in de literatuur veel sterker naar voor kwamen dan in de antwoorden op de enquêtes, is het nodig even stil te staan bij de twee ondervraagde groepen en hun context.

In de eerste plaats willen we benadrukken dat onze ondervraagde groep westerlingen hoofdzakelijk Europeanen zijn, en geen Amerikanen. Door het onderzoek te baseren op het werk van HALL, die hoofdzakelijk Amerikaanse accenten legt, is het beeld van de westerse tijd dat in de theorie geschetst werd vermoedelijk te strikt. Ook het beeld van de Rwandese tijd in de theorie is te Afrikaans, te los. Het Rwandese volk is wat bijzonder in Afrika, ook waar het tijd betreft : zij scoren "goed" als het om stiptheid en tempo gaat in vergelijking met b.v. hun Zaïrese buren. De Rwandese manier om met tijd om te gaan is voor diegenen die al met andere Afrikaanse tijdsystemen kennismaakten eerder een verademing, dan een bron van ergernis.

Het in het theoretisch deel beschreven contrast tussen westerlingen en Rwandezen was dus in oorsprong al te sterk in vergelijking met de realiteit. Er is echter nog een veel belangrijker feit dat de discrepantie tussen de theorie en de concrete onderzoeksresultaten verklaart: de aanpassing van $R$ wandezen aan westerlingen en omgekeerd, en dit op verschillende niveaus. 
Zowel op het ogenblik van de enquêtes ten opzichte van de onderzoeker als in de dagelijkse samenwerking met westerlingen passen $R$ wandezen zich aan en gedragen zich eerder westers, ook wat betreft tijd. Op deze wijze worden de westerlingen die in Rwanda werken hoofdzakelijk geconfronteerd met Rwandezen die zich "voorbeeldig" gedragen inzake tijd. Het intercultureel conflict is dan natuurlijk kleiner dan in een theoretische confrontatie van twee extremen.

Verder speelt vermoedelijk de houding van de westerlingen in Rwanda een belangrijke rol en dit in twee richtingen. Enerzijds mag men er van uitgaan dat deze vaak mensen zijn die in een zekere zin geëngageerd zijn: mensen die een ander land en zijn cultuur willen leren kennen, kunnen waarderen, en daar de nadelige kantjes bij nemen. Deze mensen staan dan ook niet zo negatief ten opzichte van het $R$ wandese tijdsysteem. Anderzijds mag men niet uit het oog verliezen dat westerlingen in Afrika altijd hogere posities bekleden, gewoon al door het feit dat men westerling is. Het is niet onwaarschijnlijk dat men daardoor met een zekere vergevingsgezindheid (neerbuigendheid?) de Rwandezen inzake tijd beoordeelde.

Ten slotte, en dit is ongetwijfeld het belangrijkste, is er op cultureel niveau een hele aanpassing aan het gebeuren in Rwanda. Het kleine midden-Afrikaanse landje beantwoordt niet langer aan het beeld dat men er van terug vindt in de literatuur. Het is een "ontwikkelingsland" in de letterlijke zin van het woord. Buiten de vele evoluties die er plaatsgrijpen (zeker de laatste twintig jaar) is vooral de afbrokkeling van hun traditionele cultuur treffend. Steeds meer "moderne" noties en gebruiken infiltreren in de Centraal-Afrikaanse cultuur. Steeds meer typisch westerse idealen en denkbeelden gaan deel uitmaken van het Rwandese gedachtengoed. Kortom, er is een Afrikaans-westers acculturatieproces aan de gang. Deze vermenging van typisch westerse cultuurelementen met het Rwandese culturele erfgoed grijpt plaats in heel Rwanda, maar in het bijzonder bij de meer geschoolde groepen van de bevolking. Deze zijn door studies, door stedelijke, industriële en commerciële ervaring intensiever blootgesteld aan westerse normen allerhande en zij hebben zich (noodgedwongen) aangepast.

Ook inzake tijd zijn het "Europeanen met een zwarte huid" geworden. In de onderzoeksresultaten vallen de hoger geschoolden uit de toon in de Rwandese antwoordgroep: hun antwoorden komen in zeer grote mate overeen met de westerse antwoordcategorieën. Dit is een vooronderstelling die door het onderzoek wordt bevestigd: men kan Rwandezen op het vlak van tijdskenmerken onderscheiden naargelang de graad van scholing die ze bereikten of, daarmee samenhangend, de mate waarin zij met westerlingen in contact gekomen zijn en samengewerkt hebben. Men kan dit betreuren of toejuichen, maar alleszins is dit eens te meer een factor die ook verklaart waarom de zwart-wit tekening van de westerse tijd ten opzichte van de Rwandese tijd na het onderzoek veel grijzer is. Onze steekproef bevatte alleen 
Rwandezen die met westerlingen hebben samengewerkt (in de ruime zin van het woord), en daarom ook relatief meer hoog geschoolden. De antwoorden neigen dan ook meer naar de westerse kant dan wat uit een willekeuriger steekproef zou blijken. Dit is echter geen fout. In de Rwandees-westerse samenwerking, zoals die in Rwanda plaatsgrijpt, komen de westerse collega's hoofdzakelijk, zoniet uitsluitend, in contact met deze "geëvolueerden", zoals ze met een etnocentrische westerse term worden bestempeld. Vooral tussen deze mensen is er interculturele communicatie !

Zo komen we dan bij de kern van dit betoog. Aanpassing, acculturatie of interculturele communicatie, is een factor die vaak over het hoofd wordt gezien. $\mathrm{Er}$ is voortdurend een snel proces van culturele uitwisseling bezig zowel tussen de beide culturen op internationaal niveau als tussen de leden van beide culturen op interpersoonlijk niveau. Hierdoor worden de sterke contrasten tussen de beide culturen minder scherp: de zwart-wit tegenstelling wordt eerder een grijsschakering.

Hierin ligt dan ook de voomaamste bijdrage van deze studie: de relativering van haar eigen titel. "Tijdsconcepten en tijdsbeleving, een probleem uit de interculturele communicatie" zou in het vervolg met een vraagteken kunnen verschijnen. Culturele spanningen als een gevolg van verschillende gewoonten en gebruiken, verschillende communicatieregels, verbale en nonverbale cultuurschatten, zijn niet gedoemd om tot kortsluitingen te leiden, wel zijn en blijven zij een belangrijk onbewust storend proces. *

* Dit artikel is gebaseerd op de eindverhandeling van de auteur, CAMMAER Gerda, Tijdsconcepten en tijdsbeleving: een probleem uit de interculturele communicatie. Case-study: Rwanda. Faculteit Sociale Wetenschappen, Departement Communicatiewetenschap, K.U.Leuven, september 1989. Promotor: prof. dr. L. Van Poecke.

NOTEN

1. Cultuur wordt in dit verband gezien als "het geheel van overgeleverde en gecreëerde waarden, overtuigingen en andere symbolisch betekenisvolle systemen en patronen ervan, als factoren die 
het menselijk gedrag vorm geven en de producten ervan" (KROEBER \& PARSONS, gecit. in DOBBELAERE, 1976: 18).

2. Wat betreft de studie van de Rwandese tijdsconcepten en tijdsbeleving werd onder andere ook beroep gedaan op linguistische studies die a.d.h.v. de woordenschat i.v.m. tijd trachten af te leiden hoe een bepaalde cultuur tijd en tijdsgebruik opvat, en op typische Rwandese spreuken. Deze laatsten hebben in Rwanda, net als in de meeste Afrikaanse landen, een veel grotere betekenis dan in het (hedendaagse) westen. Voor een Rwandees is elke spreuk een uitdrukking van wat is, wat geldt, moet of noodzakelijk is: het zijn de wetten van het dagelijks leven.

3. Polychronie of verschillende dingen tegelijkertijd doen, staat in tegenstelling met monochronie, slechts éen ding tegelijkertijd doen. In een cultuur waar monochronie de norm is, kan het mengen van allerlei activiteiten erg negatief ervaren worden: v.b. de krant lezen terwijl iemand tegen je praat geeft duidelijk te verstaan dat wat die persoon te vertellen heeft je weinig of niet interesseert.

\section{LITERATUURLIJST}

BURGOON, J.K. e.a. (1989), Nonverbal communication, the unspoken dialogue. New-York, Harper \& Row Publishers.

CONDON, J.C. en YOUSEF, F. (1981), An introduction to intercultural communication. Indianapolis, Bobbs-Merril Educational Publishing.

COUPEZ, A. (1980), L'utilisation des langues et ses problèmes, symposium "Coopération et choc de civilisations", Academie de Siences d'Outre-Mer, 14-23.

COUPEZ, A. e.a., Dictionaire Rwandais-Français, in voorbereiding.

CREPEAU, P.(1985), Parole et sagesse, valeurs sociales dans les proverbes de Rwanda. Tervuren, Koninklijk Museum voor Midden-Afrika, Annalen - Reeks IN-8X: menselijke wetenschappen nr. 118.

DESOUTER, S. (1982), Abrégé agro-pastoral du Rwanda. Paris, Agence de Coöpération Culturelle et Technique. 
d'HERTEFELT, M. en LAME, D. (1987), Société, culture et histoire du Rwanda, encyclopédie bibliographique 1863 -1980(87). Tervuren, Koninklijk Museum voor Midden-Afrika.

DOBBELARE, K. (1976), Sociologie 1. Leuven, Acco.

DRIES, H. (1986), Psycho-antropologie van de moderne Afrikaan, in: BAEKELMANS, R. en VERHOFSTADT - DENEVE, D. (red.), Ontwikkeling, persoonlijkheid en milieu, liber amicorum William De Coster. Leuven - Amersfoort, ACCO.

FAUCONNIER, G. (1986), Algemene Communicatietheorie. Leiden - Antwerpen, Mauritius Nijhoff b.v.

HALL, E.T. (1959), The silent language. Westport, Connecticut, Greenwood press.

HALL, E.T. (1982), The hidden dimension. New-York, Anchor Books, Doubleday \& Company, Inc.

ISOKO, H. (1987), Amakuru ki? Ueber Leben in Rwanda / Vivre au Rwanda. Frankfurt-Main, Verlag fur Interculturelle Kommunication.

KAGAME, A. (1956), La philosophie bantu-rwandaise de l'Etre. Brussel, Koninklijke Academie voor Koloniale Wetenschappen.

KAGAME, A. (1975), Aperception empirique du temps et conception de l'histoire dans la pensé Bantu, pp.103 -133 in RICOEUR, P. (red.), Les cultures et le temps. Paris, Payot - UNESCO.

MBITI, J.S. (1969), African religions and philosophy. London - Ibadan - Nairobi, Heineman.

MAURIER, H. (1985), Philosophie de l'Afrique noire. Bonn, Antropos-Institut St. Augustin: studia Instituti Antropos vol. 27.

NKONGORI, L. (s.d.), Proverbes du Rwanda. s.l.

POYATOS, F. (1983), New perspectives in nonverbal communication. Oxford - New-York, Pergammon Press.

RICOEUR, P. (1975), Les cultures et le temps. Paris, Payot - UNESCO.

RONDREUX, J.L. (1977), Appréhension du temps et de l'espace et l'apprentisage du vocabulaire français au Rwanda, Etudes Rwandaises, X, 2, 15-36.

ZASLAVSKY, C. (1973), Africa counts, number and pattern in African culture. Boston, Mass., Prindle, Weber \& Schmidt Inc. 